\title{
Range formula based on angle of dispersion and nozzle configuration from an impact sprinkler
}

\author{
Yue Jiang ${ }^{1}$, Zakaria Issaka ${ }^{1,2}$, Hong $\mathrm{Li}^{\mathrm{i}^{*}}$, Pan Tang ${ }^{1}$, Chao Chen ${ }^{1}$ \\ (1. Research Centre of Fluid Machinery Engineering and Technology, Jiangsu University, Zhenjiang 212013, China; \\ 2. Department of Agricultural Engineering, Tamale Technical University, Northern Region, Tamale, Ghana)
}

\begin{abstract}
Jet breakup and dispersion from impact sprinkler are mainly influenced by the configurations of nozzle and dispersion device. Based on the structure, different types of nozzles were designed and tested with a pointed tip dispersion device under low pressure conditions. Experiments were performed using High-Speed Photographic technique, and Matlab computation program was established and applied to determine the initial jet breakup length and angle of dispersion from the nozzles. The sprinkler range decreased with the increase in diameter of nozzle, and the largest range of $15.1 \mathrm{~m}$ was produced from sprinkler with $6 \mathrm{~mm}$ nozzle size under a pressure of $150 \mathrm{kPa}$. The angle of dispersion decreased with the increase of jet velocity, the spray coverage from sprinkler with $6 \mathrm{~mm}$ nozzle size was $1478 \mathrm{~mm}$ under $150 \mathrm{kPa}$, and was not statistically different when the pressure was increased. A new range formula was established for sprinkler with dispersion device through curve fitting of the parameters of initial jet breakup length, angle of dispersion, nozzle size and working pressure. The new formula was reliable for calculating range with a relative error less than $3 \%$. Since the formula is based on the angle of dispersion, it could be useful to estimate uniformity of water distribution in sprinkler irrigated fields.
\end{abstract}

Keywords: fixed dispersion device, range, jet breakup, angle of dispersion, spray coverage, impact sprinkler DOI: $10.25165 /$ j.ijabe.20191205.4646

Citation: Jiang Y, Issaka Z, Li H, Tang P, Chen C. Range formula based on angle of dispersion and nozzle configuration from an impact sprinkler. Int J Agric \& Biol Eng, 2019; 12(5): 97-105.

\section{Introduction}

Jet breakup and dispersion is an interesting and important phenomenon in irrigation engineering. Jet breakup and dispersion is important for the quality of spray from irrigation sprinklers, which is influenced by the nozzle and dispersion device. Water jet from the nozzle impinges on the dispersion device, causing it to spread and decelerate. The dispersion device breaks the jet to form droplets of variable sizes that affects the range and uniformity of sprinkler irrigation systems. Size of the wetted area and irrigation intensity are determined by sprinkler range ${ }^{[1-5]}$. Non-uniformity occurs when there are significant variations in the concentration of the droplets in an area of the irrigated field ${ }^{[6,7]}$. The sizes of the droplets affect their velocity and the range of sprinkler. Larger droplets possess greater velocities that tends to produce large sprinkler range, while the range from smaller droplet is smaller because of low velocity ${ }^{[8-11]}$.

The angle of dispersion of a jet flow can be defined base on couple methods: First, image analysis can be used to define the boundary of the jet, where the concentration of droplets is low. Second, due to the influence of air, the area with much droplet

\section{Received date: 2018-09-09 Accepted date: 2019-05-06}

Biographies: Yue Jiang, Assistant Professor, research interests: irrigation theory and technical innovation, Email: jy261715267@126.com; Zakaria Issaka, PhD Candidate, research interests: water-saving irrigation theory and technical innovation, Email: issakazak@gmail.com; Pan Tang, Assistant Professor, research interests: irrigation theory and technical innovation, Email: tangpan19@163.com; Chao Chen, Associate Research Fellow, research interests: design of water-saving irrigation equipment, Email: chch3605@, ujs.edu.cn.

*Corresponding author: Hong Li, Professor, research interests: design of water-saving irrigation equipment. Research Center of Fluid Machinery Engineering and Technology, Jiangsu University, No.301 Xuefu Road, Zhenjiang 212013, China. Tel: +86-13952891655, Email: hli@ujs.edu.cn. concentration can be used to define a spray cone. An estimate of jet dispersion of a single cone angle is useful in practice ${ }^{[12-19]}$. The cone angle represents two lines that penetrate the spray at a specific distance. Formulas expressing the angle of dispersion for jet were previously developed ${ }^{[20-22]}$. The angle of dispersion was correlated with liquid flow rate, pressure, nozzle dimensions, air properties and liquid properties. The concept of penetration and breakup of jet was used to describe the flow dynamics ${ }^{[23]}$, and also useful in modeling and design ${ }^{[24]}$. Similarly, CFD was used to determine droplet dispersion characteristics ${ }^{[25]}$. The distributions of droplets from a parallel jet was simulated by using LaGrange simulation $^{[26]}$. However, these methods are difficult and expensive to apply.

In general, the working pressures can be divided into three categories in sprinkler irrigation: low-pressure: $\leq 200 \mathrm{kPa}$; intermediate pressure: $200-400 \mathrm{kPa}$; high-pressure: $\geq 400 \mathrm{kPa}$. Impact sprinklers are classified under intermediate pressure, with pressure ranges in $250-300 \mathrm{kPa}$. Since the configurations of nozzle are associated with the dispersion device, studies on dispersion characteristics and sprinkler range is necessary. By using these concepts, irrigation designers can predict the spray coverage and relate it to irrigation uniformity. Currently, no work has been done using the angle of dispersion as a function of nozzle diameter and dispersion device. In this study, the initial breakup length and the angle of dispersion were determined and correlated with the diameter of nozzle and sprinkler range, which could be used as an easy, less cost and reliable way to model and design the nozzle and dispersion devices for impact sprinklers.

\section{Materials and methods}

\subsection{Structure of impact sprinkler with dispersion device}

The impact sprinkler of size $25.4 \mathrm{~mm}$ (model number 3521A) from Davide and Luigi Volpi Spa, Casalromano (CM), Italy was 
used as the test object in the experiment. The sprinkler nozzle is plastic and circular-shaped with standard inlet and outlet diameters of 18 and $8 \mathrm{~m}$, respectively. The dispersion arm was firstly screwed to the sprinkler, and then the dispersion device was inserted into a spring and screwed into the holder of the water dispersion device. The complete arrangement was mounted on the sprinkler using a screw. As the jet flows from the nozzle and impact on the deflector, the sprinkler is driven into rotation. The deflector arm is repeatedly pushed back into the jet flow by a spring-loaded arm each time it comes into contact with the jet flow. The deflector arm slightly changes the flow and disperses the water around the sprinkler. The spring provides vertical stability to the fixed water dispersion device during jet flow impact. As shown in Figure 1, the tip of the dispersion device protrudes into the jet flow. As the jet impinged the fixed dispersion device, the flow was interrupted, which caused a change in linear momentum and finally break up and disperse the jet. As a result, the inertia and momentum of the droplets are decreased, and the droplets fall near the sprinkler.

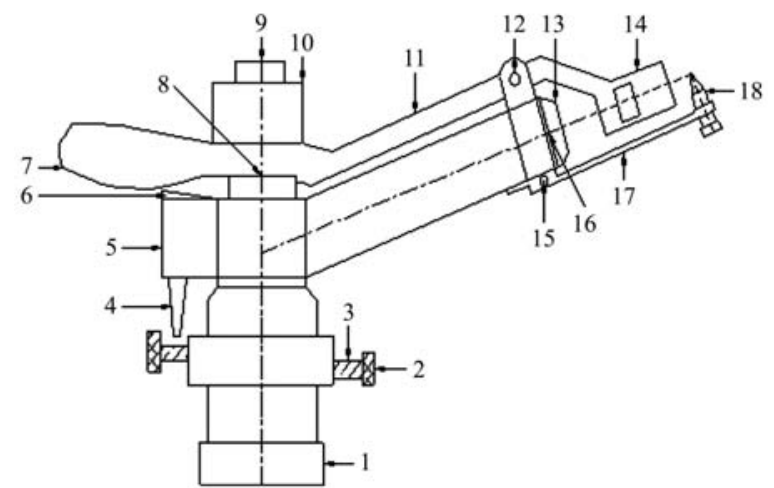

1. Bearing assemble 2. Shift lever 3. Spring 4. Snap level 5. Swing level 5. Stop shifter 6. Casing lever 7. Impulse arm 8. Bearing assemble 9. Inverted U-shaped mounted structure 10 . Sprinkler head body 11. Impulse arm 12. Screw for arm 13. Nozzle 14. Deflector 15. Screw for device 16. Nozzle assembly 17. Holder for the dispersion device 18. Fixed water dispersion device.

Figure 1 Structural diagram of the impact sprinkler

\subsection{Structure of nozzles}

The impact sprinkler with a newly designed dispersion device of depth $4.5 \mathrm{~mm}$ in the jet was used as test object. The impact arm was removed and reversed in position to be allowed for the tests. The outlet diameters of the nozzle that were tested with the impact sprinkler including $4 \mathrm{~mm}, 6 \mathrm{~mm}, 8 \mathrm{~mm}, 10 \mathrm{~mm}$ and $12 \mathrm{~mm}$. Figure 2a presented the sizes of the nozzles, in which $D_{1}$ is the outlet diameter of jet, $D_{2}$ is the inlet diameter of jet, $\theta$ is the cone angle of nozzle, and $L$ is the total length of nozzle. Prototypes of the nozzles can be found in Figure 2b, while the technical parameters of the nozzles used in the experiment were listed in Table 1.

\subsection{Jet dispersion theory}

As presented in Figure 3 and Figure 4, the Initial breakup process involves the breakup of the jet flow from the nozzle upon impingement on the dispersion device, and secondary breakup describes the final breakdown of droplets ${ }^{[27]}$. The angle of dispersion widens in relation to the vertical axis. As illustrated in the figure below, the spray angle tends to reduce or increase with the increase of distance from the point of spray. The distance through the centerline of the jet where the velocity is zero or attained half the axial velocity is what creates the initial breakup of the jet ${ }^{[28]}$.
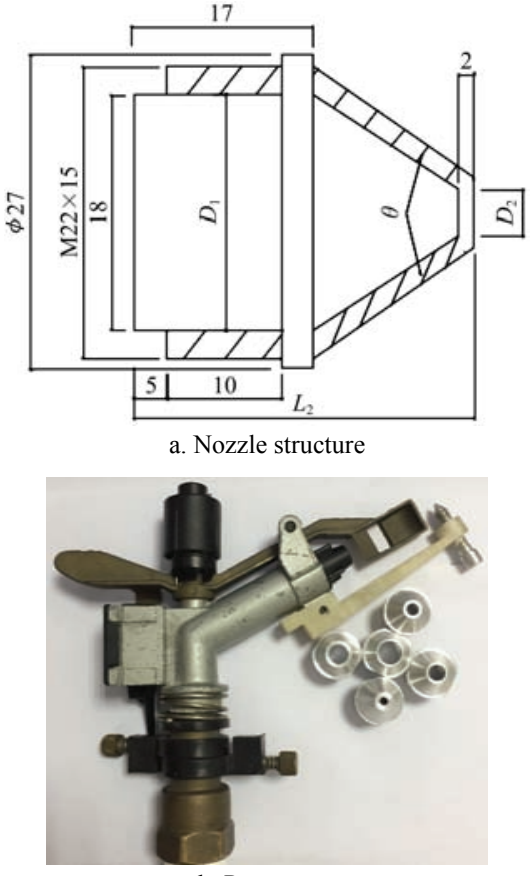

b. Prototypes

Figure 2 Structure of the nozzles and prototypes for impact sprinkler

Table 1 Technical parameters of nozzles used in experiment

\begin{tabular}{ccccc}
\hline Nozzle type & $D_{1} / \mathrm{mm}$ & $D_{2} / \mathrm{mm}$ & $\theta /\left(^{\circ}\right)$ & $L / \mathrm{mm}$ \\
\hline A & 17 & 4 & 30 & 23 \\
B & 17 & 5 & 32 & 25 \\
C & 17 & 6 & 34 & 28 \\
D & 17 & 8 & 37 & 29 \\
E & 17 & 10 & 39 & 31 \\
\hline
\end{tabular}

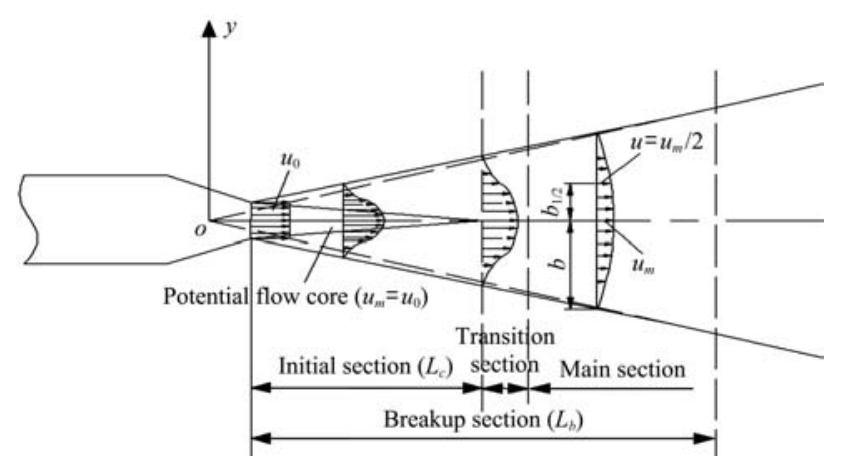

Figure 3 Schematic model of jet from sprinkler without dispersion device

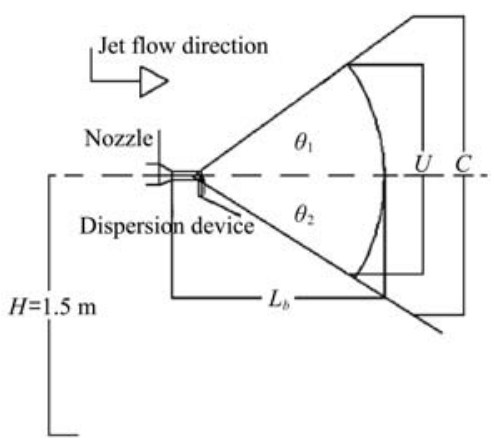

Note: $y$ is the depth of the fixed water dispersion device in jet, mm; $\theta\left(\theta_{1}+\theta_{2}\right)$ is the angle of dispersion; $L_{b}$ is the initial breakup length, mm; $U$ is uniformity, \%; $C$ is the spray coverage, $\mathrm{mm} ; U_{m} / 2$ is the radial location where jet velocity has decayed to half of centerline value.

Figure 4 Schematic model of jet from sprinkler with dispersion device 
From the nadir view, the angles of dispersion above and below the centerline are different and are represented by $\theta_{1}$ and $\theta_{2}$, respectively. The spray coverage $(C)$ at specific distances for angles below $180^{\circ}$ were calculated using the Equation (3) below. The boundaries of the jet were demarcated and the angle between the boundaries and centerline was specified as the dispersion angle ${ }^{[29]}$. It has a great influence on range and uniformity in sprinkler irrigation. The calculation formula of the spray angle is given as;

$$
\theta=\tan ^{-1}\left[\frac{r_{1 / 2}}{x}\right]
$$

Figure 5 presented the development of a mathematical model by using Matlab computation program as given in equation 2 below. The different photographs captured during the experiments were applied into the computation program and the angles of dispersion from different types of nozzles were computed.

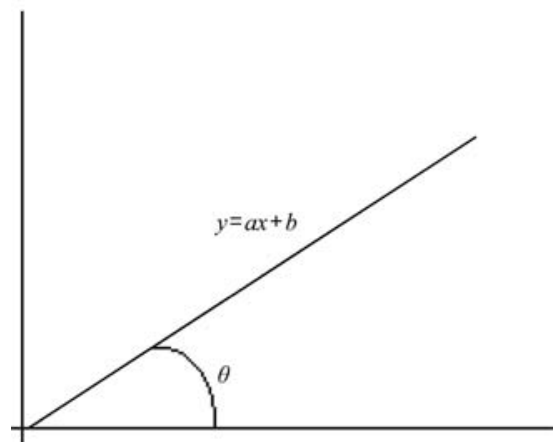

Figure 5 Mathematical model of the angle of jet dispersion

$$
\theta=\tan ^{-1}\left[a b s\left(\frac{a-b}{1+a+a b}\right) \times \frac{180}{\pi}\right]
$$

Spray coverage or spreading rate refers to the ratio of the jet half-width $\left(U_{m} / 2\right)$ to the axial distance, where jet velocity has decayed to half of the centerline value. It reflects the degree of water distribution, and its significance on the growth of crops is a measurement of the quality of sprinkler irrigation. The calculating formula for spray coverage is given as;

$$
C=2 L_{b} \tan \left(\frac{\theta}{2}\right)
$$

where, $L_{b}$ is the axial spray distance to the initial jet breakup point, $\mathrm{mm}$; and $\theta$ is the angle of dispersion, $\left({ }^{\circ}\right)$.

\subsection{Measurement of range}

Catch cans were arranged in 2 rays spaced $1.0 \mathrm{~m}$ apart with a uniform angle, and the sprinkler position was used as the center. The distance from the point with irrigation intensity of $0.3 \mathrm{~mm} / \mathrm{h}$ (the point with irrigation intensity of $0.15 \mathrm{~mm} / \mathrm{h}$ when the spray flow below $0.25 \mathrm{~m}^{3} / \mathrm{h}$ ) to the center of sprinkler was defined as the sprinkler range ${ }^{[23]}$. The test time was $1 \mathrm{~h}$, and the average value of three repeated experiments was considered as sprinkler range.

\subsection{HSP experiment}

The High-Speed Photography (HSP) experiment was carried out at the sprinkler Irrigation Hall of Jiangsu University in China. During the tests, the impact arm of the impact sprinkler was reversed from normal position to one direction that maintaining the spray. This allowed for the image shooting and observation of the flow behaviors. Tests were performed by using a dispersion device with an insertion depth of $4.5 \mathrm{~mm}$, while changing the nozzle sizes of 4, 5, 6, 8 and $10 \mathrm{~mm}$. The technical details of the nozzles can be found in Table 1. The experiment was performed using a High-Speed camera which was set to $0.1 \mathrm{~ms}$ for each frame in the test according to ISO standard ${ }^{[30]}$. The exposure time was set at $5 \mu \mathrm{s}$. For the experiment with shadow method, the optical system consists of a $1000 \mathrm{~W}$ camera light and a piece of ground glass. The light goes through the jet flow while flow fluctuates, then a shadow image of jet and surface wave is captured by the camera. The ground glass was used to attenuate the light. To capture clearer images, a $100 \mathrm{~mm}$ micro-lens was configured on the camera. The $1000 \mathrm{~W}$ camera light was used to produce straight beam. A dark board was placed at the back of the observation area, and the jet was illuminated by the light horizontal to the area captured as shown in Figure 6 below.
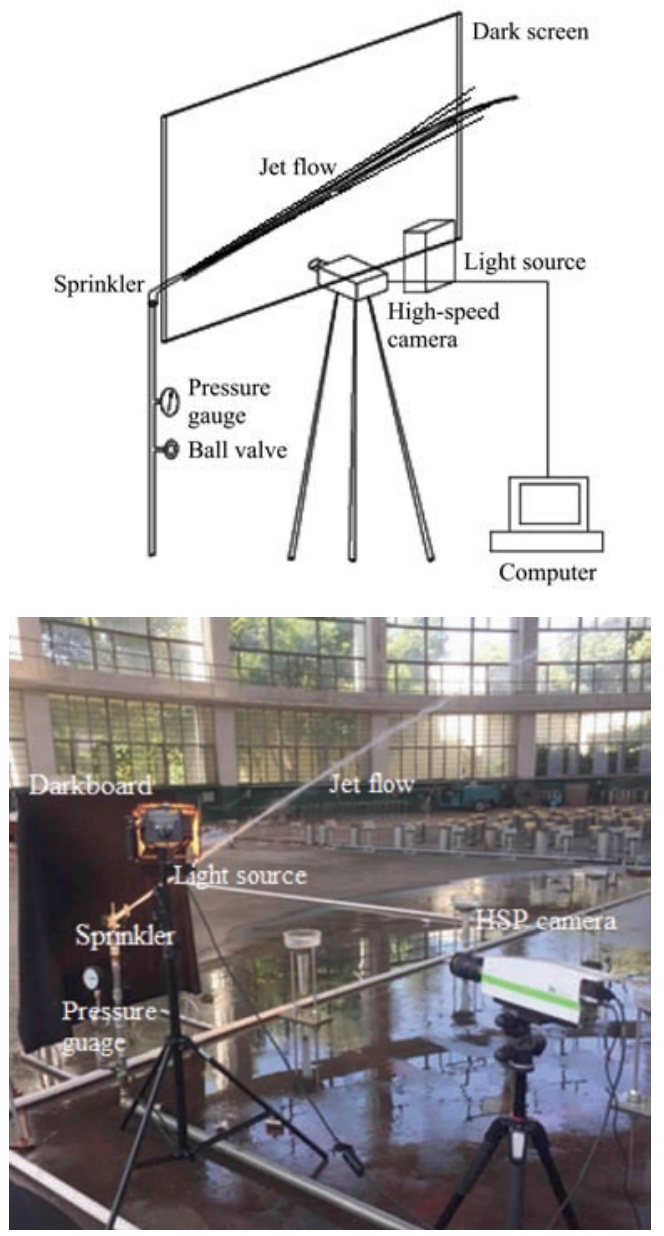

Figure 6 Experimental setup of jet breakup and dispersion

During the experiments, the working pressure was varied from $100-200 \mathrm{kPa}$. The conditions of water and air used in the experiment were listed in Table 2.

Table 2 Parameters of water and air used in the experiment.

\begin{tabular}{lc}
\multicolumn{1}{c}{ Parameter } & Value \\
\hline Temperature in the $\mathrm{Lab} /{ }^{\circ} \mathrm{C}$ & 20 \\
Density of water $/ \mathrm{kg} \cdot \mathrm{m}^{-3}$ & 998 \\
Viscosity $/ \mathrm{kg} \cdot \mathrm{m} \cdot \mathrm{s}^{-1}$ & $1.01 \times 10^{-3}$ \\
Density of air $/ \mathrm{kg} \cdot \mathrm{m}^{-3}$ & 1.293 \\
Wind speed $/ \mathrm{m} \cdot \mathrm{s}^{-1}$ & 0.00 \\
Viscosity of air $/ \mathrm{kg} \cdot \mathrm{m} \cdot \mathrm{s}^{-1}$ & $1.79 \times 10^{-5}$ \\
Surface tension of water $/ \mathrm{N} \cdot \mathrm{m}^{-1}$ & 0.072 \\
Velocity air $/ \mathrm{m} \cdot \mathrm{s}^{-1}$ & $0.1-0.5$ \\
Friction factor & $\approx 0.00$ \\
Nozzle height $/ \mathrm{m} \cdot \mathrm{s}^{-1}$ & 1.5 \\
Inclination angle of the jet $/\left({ }^{\circ}\right)$ & 23 \\
\hline
\end{tabular}




\subsection{Range formula}

Four formulas of range applied locally and internally were compared with the Cauazza Equation (4), Chang W H Equation (5), Jia W L Equation (6), Feng C D Equation (7), Gan Z M Equation (8), and Jiang Y Equation (9) listed below ${ }^{[31]}$

$$
\begin{gathered}
R=1.35 \sqrt{D_{2} p} \\
1.70 D_{2}^{0.487} p^{0.45} \\
0.415 D_{2}^{3} \sqrt{\frac{\alpha}{\pi} \times 1.8 \times 10^{5}\left(\frac{P}{10^{4}}\right)^{2 / 3}} \\
R=4 \mu^{2} \rho \sin ^{2} \theta\left(\cot \theta-0.216 \frac{\rho^{0.94}}{D^{2}}\right) \\
R=\xi \rho^{m} D_{2}^{n} \\
R=0.7273\left(\frac{U_{0}}{S_{\max }} \operatorname{In} \frac{\alpha}{\eta}\right)^{0.4831}
\end{gathered}
$$

where, $R$ is the spray range, $\mathrm{m} ; D_{2}$ is the nozzle diameter, $\mathrm{m} ; p$ is the working pressure, $\mathrm{kPa} ; \alpha$ is the elevation angle of the jet, $\left(^{\circ}\right)$; $\mu$ is the kinematic viscosity, $\mathrm{m}^{2} / \mathrm{s} ; U_{o}$ is initial velocity, $\mathrm{m} / \mathrm{s} ; S_{\max }$ is maximum perturbation growth rate, $\mathrm{mm} / \mathrm{s}$; and $\xi$ is a coefficient.

\subsection{Discharge}

The discharge from the nozzles was calculated by using the equation below.

$$
Q=c A(2 g H)^{2}
$$

where, $Q$ is the nozzle discharge rate, $\mathrm{m}^{3} / \mathrm{s} ; A$ the is cross-sectional area of the nozzle, $\mathrm{m}^{2} ; g$ is the gravitational acceleration, $\mathrm{m} / \mathrm{s}^{2} ; H$ is the pressure head, $\mathrm{m} ; c$ is the discharge coefficient; and $x$ is the discharge exponent.

\section{Results and discussion}

\subsection{Discharge and sprinkler range}

With respect to the discharge, several studies deduced the discharge exponent as independent of pressure for a given nozzle diameter, and the discharge exponent is constant that equal to $0.5^{[32]}$. In this study, the discharge exponent was also assumed to be equal to 0.5 . The equation was allowed to calculate the flow rate for each nozzle diameter, and the discharge coefficients were presented in Table 3. The discharge coefficient increased with the increase in pressure and remained unchanged for each of the nozzles tested. Sprinkler with type B nozzle gave $c$ values which ranged from 0.67 to 0.93 with an average of 0.83 under a pressure of $150 \mathrm{kPa}$. However, it can be observed that the differences between the $\mathrm{c}$ values were between 0.1 and 0.2 , which could be due to pressure fluctuations from the pump. This means that the discharge coefficient was more dependent on the nozzle size rather than pressure. Similar findings were previously reported ${ }^{[33,34]}$.

The sprinkler ranges increased with the increase of pressure, and the largest ranges were produced from sprinkler without dispersion device. This was expected because without any interruption by the fixed dispersion device, the jet travels longer. Meanwhile, the sprinkler ranges firstly increased, and subsequently decreased when the outlet diameter of the nozzle was raised from 4 to $12 \mathrm{~mm}$, which agrees with previous studies of the relationship between nozzle size and sprinkler range ${ }^{[35]}$. As an example, the sprinkler range from sprinkler with type B $(6 \mathrm{~mm})$ nozzle was

\begin{tabular}{|c|c|c|c|c|c|c|}
\hline \multirow{3}{*}{$\begin{array}{c}\text { Nozzle } \\
\text { type }\end{array}$} & \multicolumn{3}{|c|}{ Discharge coefficient $(c)$} & \multicolumn{3}{|c|}{ Sprinkler range $/ \mathrm{m}$} \\
\hline & \multicolumn{6}{|c|}{$\mathrm{P} / \mathrm{kPa}$} \\
\hline & 100 & 150 & 200 & 100 & 150 & 200 \\
\hline A & 0.67 & 0.69 & 0.70 & 8.3 & 13.1 & 12.2 \\
\hline B & 0.76 & 0.78 & 0.79 & 10.4 & 15.1 & 14.9 \\
\hline $\mathrm{C}$ & 0.78 & 0.81 & 0.83 & 12.2 & 16.1 & 16.7 \\
\hline $\mathrm{D}$ & 0.85 & 0.86 & 0.87 & 12.9 & 16.5 & 14.5 \\
\hline $\mathrm{E}$ & 0.91 & 0.92 & 0.93 & 13.8 & 17.1 & 15.4 \\
\hline
\end{tabular}
$15.1 \mathrm{~m}$, and the coefficient of variations value was only $1.6 \%$ under $150 \mathrm{kPa}$. With an increase in pressure, the coefficient of variations also increased with a value of $3.7 \%$, and a non-significant difference $(p>0.05)$ was found between $150 \mathrm{kPa}$ and $200 \mathrm{kPa}$.
Table 3 Coefficient of discharge and ranges for nozzle types and pressures

Sprinkler range was dependent upon the diameter of the cylindrical jet between the nozzle and the dispersion device, which influences the degree of interruption and the distance that dispersed droplets can travel. For the sprinkler with $6 \mathrm{~mm}$ nozzle size, it was possible that part of the jet had greater interruption, while the other upper part of the jet flowed past with little interruption by the dispersion device to maintain a large sprinkler range.

\subsection{Characteristics jet breakup and dispersion}

Photographs were taken from the sprinkler with different sizes of nozzles and pressures for analysis (Figure 7a). When the sprinkler was run without the dispersion device, the jet was plain, and the surface boundary can be seen to slightly enlarged due to increase in flow friction as the jet flows. With an increase in pressure, the surface boundary of the plain jet remained smooth, and no droplets can be seen in the observation area. Without the dispersion device, jet breakup only occurred due to collision with surrounding air at a distance far away from the sprinkler. Influence of the surrounding air causes fragmentation in the plain jet, which increases when the air is entrained ${ }^{[36]}$.

The sprinklers with different types of nozzles were tested with the fixed dispersion device protruding into the jet. Upon impingement on the dispersion device, the jet breaks up, resulting in rough surface flow at the initial breakup section with a mixture of water and air. When the jet reached the breakup section, the air surface force to jet was greater than the surface tension and make the jet broken, giving more droplets near the sprinkler as can be seen in Figure 7b. Variations in the sizes, amount of droplets and the initial breakup lengths were observed according to the type of nozzle that tested with the sprinkler. As can be seen in the figure, the jet flow direction is from left to right, and the distance from nozzle to where the initial breakup occurred was defined as the initial jet breakup length $\left(L_{b}\right)$. Circles were marked at the first breakup point to describe the initial breakup length, while arrows were used to show the dispersed droplets. An interesting phenomenon can be seen when the sprinkler was tested with different sizes of the nozzles. For example, sprinkler with type B nozzle $(6 \mathrm{~mm})$ produced the best droplets sizes, and the initial breakup length of the jet was longer under a pressure of $150 \mathrm{kPa}$ (Figure 7c). A greater part of the jet was interrupted by the dispersion device, giving more droplets.

A general trend was discovered that the droplets became smaller and the initial breakup lengths became longer when the pressure was increased, particularly in the case of types C and D nozzles (Figures 7d and 7e). However, when nozzles with large outlet diameter were applied, it was possible that a larger part of the jet was uninterrupted by the dispersion. Hence, the initial breakup lengths were comparatively longer, and the sizes of the droplets produced were much larger. 


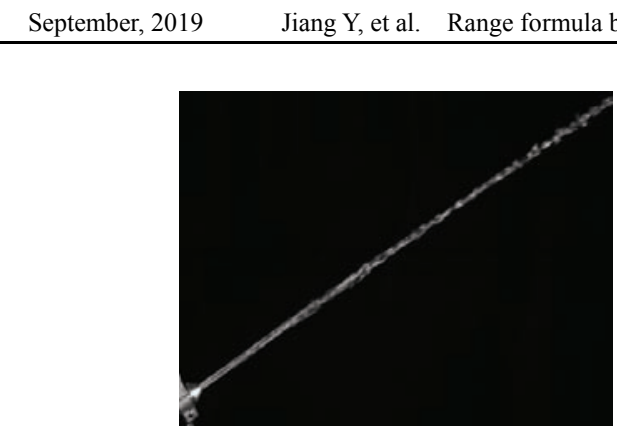

$100 \mathrm{kPa}$

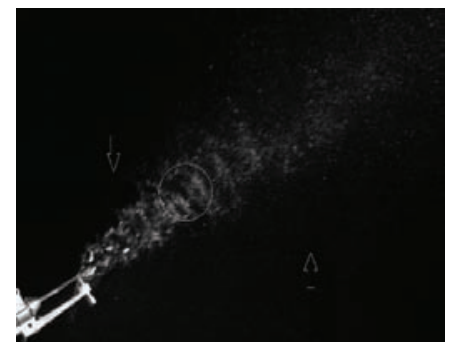

$100 \mathrm{kPa}$

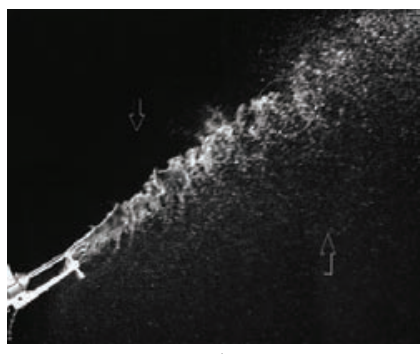

$100 \mathrm{kPa}$

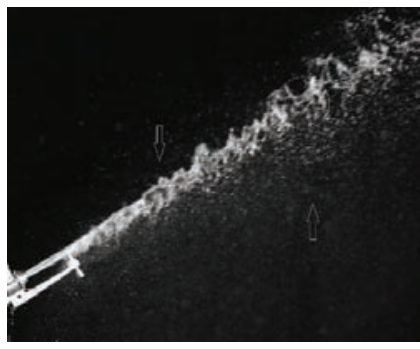

$100 \mathrm{kPa}$

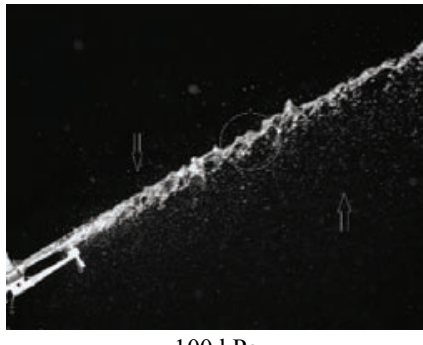

$100 \mathrm{kPa}$

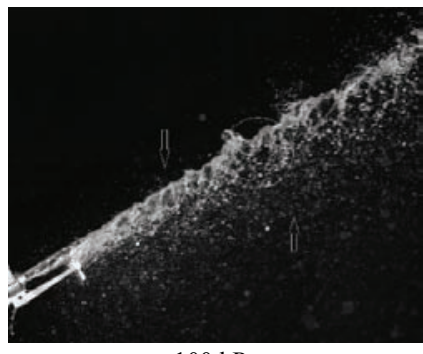

$100 \mathrm{kPa}$

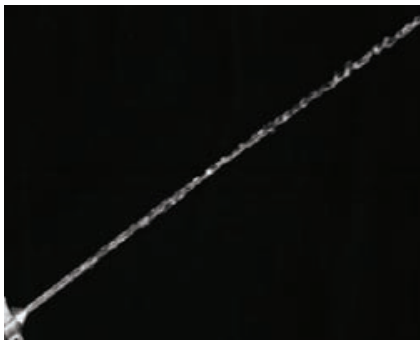

$150 \mathrm{kPa}$

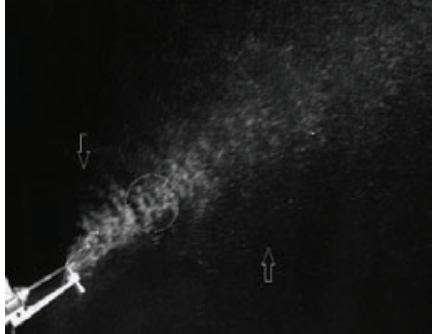

$150 \mathrm{kPa}$

b. Jet from sprinkler with type A nozzle

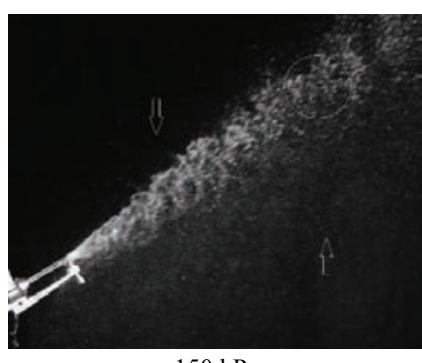

$150 \mathrm{kPa}$

c. Jet from sprinkler with type B nozzle

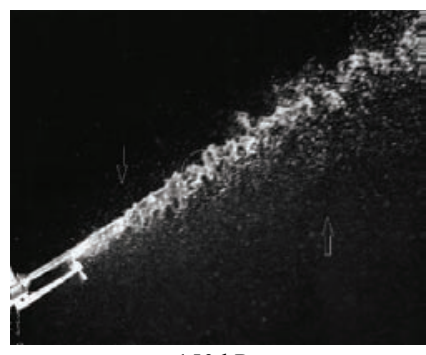

$150 \mathrm{kPa}$

d. Jet from sprinkler with type $\mathrm{C}$ nozzle

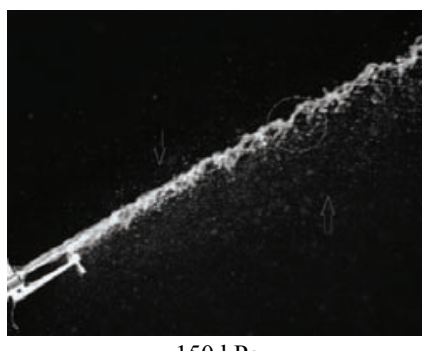

$150 \mathrm{kPa}$

e. Jet from sprinkler with type D nozzle

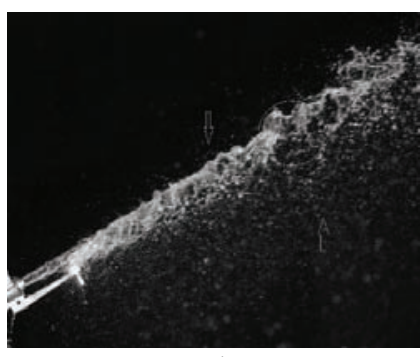

$150 \mathrm{kPa}$

f. Jet from sprinkler with type E nozzle

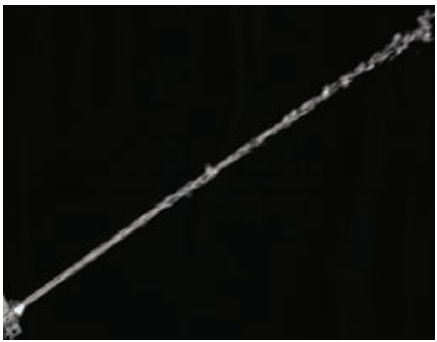

$200 \mathrm{kPa}$

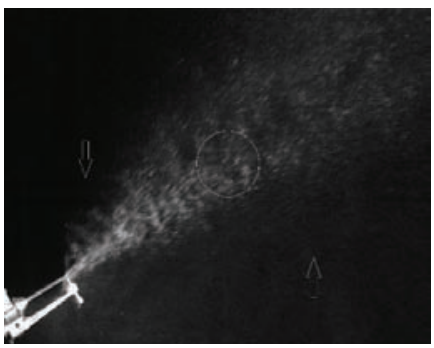

$200 \mathrm{kPa}$

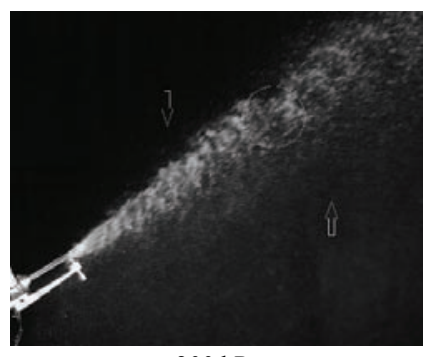

$200 \mathrm{kPa}$

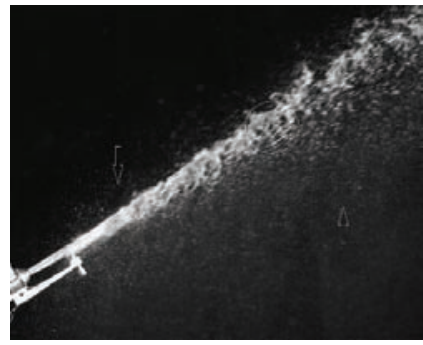

$200 \mathrm{kPa}$

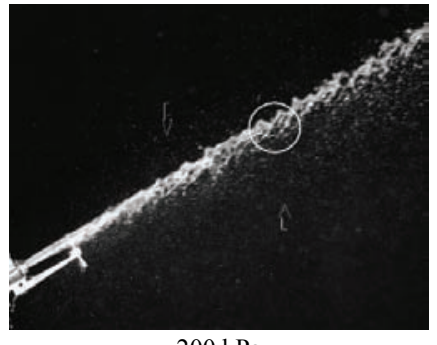

$200 \mathrm{kPa}$

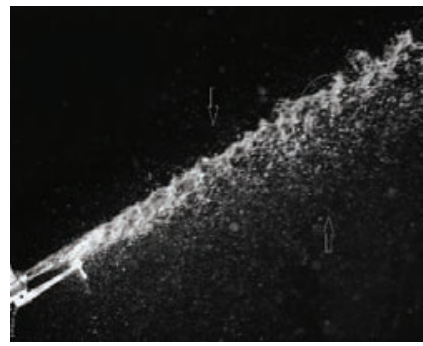

$200 \mathrm{kPa}$

Figure 7 Jet breakup and dispersion from nozzles under different pressures 


\subsection{Initial breakup length and jet velocity}

The distance from the outlet of the nozzle to the point where the first breakup occurred in the jet flow was measured by applying the photographs in Matlab computation. Variations in the initial breakup lengths of the jet along the jet flow direction can be observed according to the size of the nozzle that was tested with the sprinkler. It was discovered from Figure 8 that the initial breakup lengths of the jet decreases when the outlet diameter of the nozzle is smaller. This occurred because there was greater interruption by the dispersion device, causing an early breakup in the jet flow. The initial breakup length was mainly influenced by the nozzle size. The smaller size of the nozzle creates smaller initial breakup length, and the reverse is also true. By maintaining the nozzle size under varying jet velocity, the initial breakup lengths decreased with the increase of jet velocity. For example, the initial breakup lengths from the sprinkler with type B $(6 \mathrm{~mm})$ nozzle decreased from $2600 \mathrm{~mm}, 2210 \mathrm{~mm}$, and 1860 for jet velocities of $36.2 \mathrm{~m} / \mathrm{s}$, $45.3 \mathrm{~m} / \mathrm{s}$ and $58.4 \mathrm{~m} / \mathrm{s}$, respectively.

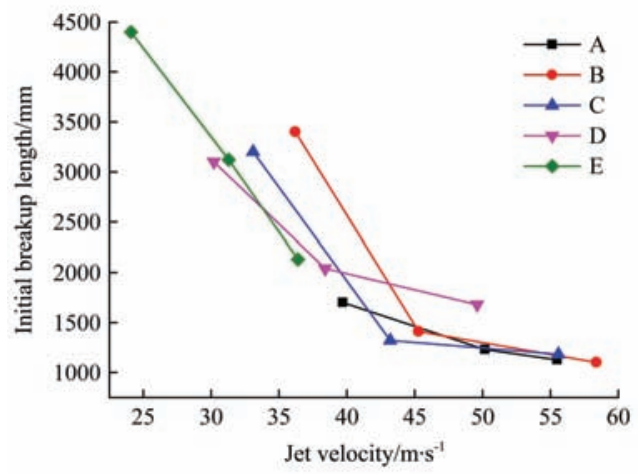

Figure 8 Relationship between initial breakup length and jet velocity

The coefficients of variation under $150 \mathrm{kPa}$ and $200 \mathrm{kPa}$ were $1.1 \%$ and $2.5 \%$ respectively, which was not significantly different $(p>0.05)$ when the jet velocity was increased. The reason for this observation could be that the interruption by the dispersion device on the jet flow was greater when the jet velocity was further increased. This means that the nozzle size was the main influencing factor on the initial breakup length compared with jet velocity, which also indicates a good trend with the intensification of flow instability for smaller nozzles.

\subsection{Dispersion angle and spray coverage}

The obtained photographs were applied into the Matlab computation program to determine the angles of dispersion from different types of nozzles. Figure 9 presents the relationship between the angle of dispersion and jet velocity from the nozzles. The nozzles produced different angles of dispersion under varying pressure conditions, which means the size of the nozzle was a main influencing factor. The nozzle with smaller diameter $(4 \mathrm{~mm})$ gave a wide angle of dispersion, which was increased with the increase of jet velocity. The diameter of the cylindrical jet before the impact was less than the insertion depth of the dispersion device, hence the interruption was greater with large spreading of the jet. However, the increment of the angle of dispersion was smaller as the size of the nozzle was larger. Smaller nozzles such as the ones tested with the sprinkler in this study produced an angle of dispersion that increased with increasing jet velocity. The finding conforms with previous work, which also shows that increasing jet velocity leads to a wider angle of dispersion ${ }^{[37,38]}$. As presented in Figure 9e, the sprinkler with type B nozzle $(6 \mathrm{~mm})$ gave an angle of dispersion which increased from $31.8^{\circ}$ to $33.7^{\circ}$ when the jet velocity was increased from $36.2 \mathrm{~m} / \mathrm{s}$ to $48.3 \mathrm{~m} / \mathrm{s}$, and the coefficient of variations was less than $2.6 \%$. And the relationship between jet velocity and the angle of dispersion for the sprinkler with $6 \mathrm{~mm}$ nozzle was almost linear. This means that the $6 \mathrm{~mm}$ nozzle can be used together with the dispersion device with an insertion depth of $4.5 \mathrm{~mm}$ to effectively improve jet dispersion.

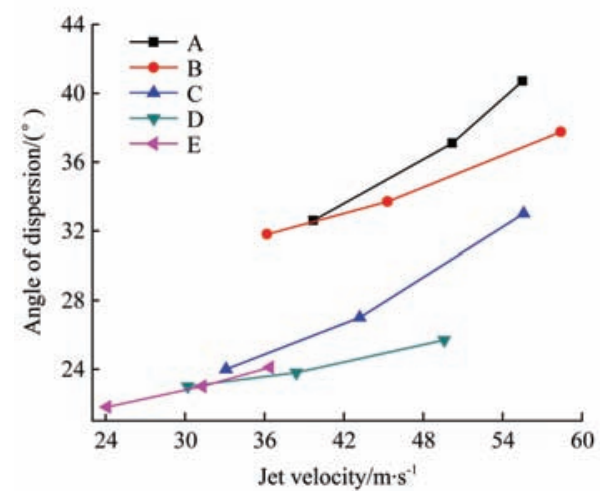

Figure 9 Relationship between angle of dispersion and jet velocity

Spray coverage affects uniformity from sprinklers. The larger the spray coverage, the better the uniformity produced from irrigation sprinklers. In this study, the spray coverage from the nozzle was calculated based on the axial spray distance $\left(L_{b}\right)$ or initial breakup length, which was from the point of impingement on the dispersion device to the initial jet breakup point. Results of the spray coverages from the sprinkler with different types of nozzles are presented in Table 4. The spray coverage was larger with the increase of pressure, and decreased when the outlet diameter of the nozzles was larger. Spray coverage from sprinkler with type B nozzle was largest (1478 mm under $150 \mathrm{kPa})$, which increased slightly to a value of $1677 \mathrm{~mm}$ with the increase of pressure.

Table 4 Spray coverage for different types of nozzles and pressures

\begin{tabular}{cccc}
\hline & \multicolumn{3}{c}{ Spray coverage/mm } \\
\cline { 2 - 4 } Nozzle type & \multicolumn{3}{c}{$\mathrm{P} / \mathrm{kPa}$} \\
\cline { 2 - 4 } & 100 & 150 & 200 \\
\cline { 2 - 4 } $\mathrm{A}$ & 9840 & 1062 & 1371 \\
$\mathrm{~B}$ & 1509 & 1478 & 1677 \\
$\mathrm{C}$ & 1219 & 1272 & 1485 \\
$\mathrm{D}$ & 1099 & 1232 & 1565 \\
E & 8910 & 1116 & 1274 \\
\hline
\end{tabular}

However, no significant difference $(p>0.05)$ was found, which means that the sprinkler with $6 \mathrm{~mm}$ can be used together with the dispersion device to improve water distribution uniformity in the middle of the range and near the sprinkler under low pressure conditions.

\subsection{Range formula}

Special attention was given to the development of range formula by using least square method to obtain the regression coefficient by fitting out the range in relation to the initial jet breakup length, angle of dispersion, nozzle size and working pressure. It is worthy to note that the new formula is different from other range formulas, since it is applicable to a sprinkler with a dispersion device. The formula of range of the sprinkler with dispersion device is given as.

$$
R=1.2 p^{0.650} D_{2}^{0.611} L_{b}^{0.420} \tan \theta
$$


where, $R$ is range, $\mathrm{m} ; D_{2}$ is outlet diameter of nozzle, $\mathrm{mm} ; p$ is pressure, $\mathrm{m} ; \theta$ is angle of dispersion, $\left({ }^{\circ}\right)$; and $L$ is initial breakup length of jet, $m$.

\subsection{Comparison of calculated and measured ranges}

Results of the relative errors between the measured and calculation values of range for different types of nozzles were presented in Table 5. The relative errors between the calculated and the measured ranges were below $2.4 \%$, which means the new formula was better for calculation of sprinkler range.

\subsection{Comparison with other formulas}

Figure 10a presents the relationship between range and different diameters of the nozzles tested with the sprinkler. The sprinkler range increased with the increase of nozzle diameter. However, the increasing trend of ranges was slightly reduced when the diameters of the nozzles were 10 and $12 \mathrm{~mm}$. Cauazza and Chang formulas gave large relative errors of $11.2 \%$ and $12.6 \%$, respectively. However, the new formula agrees with the existing formulas, and the relative error was less than $10 \%$. The relative errors of the ranges from Jia, Feng, Gan and Jiang formulas were $4.6 \%, 3.8 \%, 2.7 \%, 3.4 \%, 1.9 \%, 2.5 \%, 1.3 \%$, and $5.4 \%$, respectively. Range in the new formula was determined by the diameter of the nozzle and angle of dispersion caused by the impingement of the jet flow on the fixed dispersion device.

With the increase of pressure from $100 \mathrm{kPa}$ to $150 \mathrm{kPa}$, the ranges from the new formula increased, and slightly reduced when pressure raise to $200 \mathrm{kPa}$ (Figure 10b). As can be seen in the figure, the sprinkler range reduce as the pressure increased to high level, which reinforces the point that dispersion device is helpful under low pressure conditions. Existing formulas indicated a large relative error, but their applications are limited because only the diameter of nozzle and pressure were considered. The new fitting formula in this study considered the initial breakup length, dispersion angle, and agrees with other formulas, which means that the new formula could offer a wider scope, particularly for sprinklers with dispersion device.

3.8 Relationship between diameter of nozzle and $R e, W e$

In Figure 11, the nozzle with outlet diameter of $6 \mathrm{~mm}$ gave the largest $R e$, which means that the nozzle produces the largest turbulence and the difference tend to increase with the increase of pressure. Moreover, the nozzles were similar in terms of jet velocity and fluid viscosity, hence the variation in $R e$ was caused by hydraulic diameters.

Table 5 Comparison of ranges for different types of nozzles and pressures

\begin{tabular}{|c|c|c|c|c|c|c|c|c|c|}
\hline \multirow{3}{*}{ Nozzle type } & \multicolumn{9}{|c|}{ Pressure $/ \mathrm{kPa}$} \\
\hline & \multicolumn{3}{|c|}{100} & \multicolumn{3}{|c|}{150} & \multicolumn{3}{|c|}{200} \\
\hline & $\mathrm{CF} / \mathrm{m}$ & $\mathrm{MF} / \mathrm{m}$ & $\mathrm{RE} / \%$ & $\mathrm{CF} / \mathrm{m}$ & $\mathrm{MV} / \mathrm{m}$ & $\mathrm{RE} / \%$ & $\mathrm{CF} / \mathrm{m}$ & $\mathrm{MV} / \mathrm{m}$ & $\mathrm{RE} / \%$ \\
\hline $\mathrm{A}$ & 8.1 & 8.3 & 2.409 & 12.8 & 13.1 & 2.290 & 11.9 & 12.2 & 2.459 \\
\hline B & 10.2 & 10.4 & 1.923 & 15.4 & 15.1 & 1.986 & 15.3 & 14.9 & 2.684 \\
\hline $\mathrm{C}$ & 12.1 & 12.2 & 0.819 & 16.3 & 16.1 & 1.242 & 17.1 & 16.7 & 2.395 \\
\hline $\mathrm{D}$ & 13.2 & 12.9 & 2.277 & 16.7 & 16.5 & 1.212 & 14.9 & 14.5 & 2.758 \\
\hline $\mathrm{E}$ & 14.1 & 13.8 & 2.127 & 17.4 & 17.1 & 1.754 & 15.7 & 15.4 & 1.948 \\
\hline
\end{tabular}

Note: $\mathrm{CF}$ is calculated value, $\mathrm{ME}$ is experimental value, and $\mathrm{RE}$ is relative error.

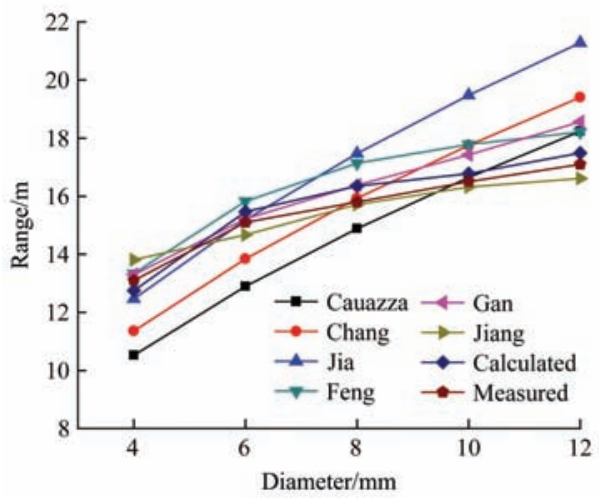

a. Range and nozzle diameter

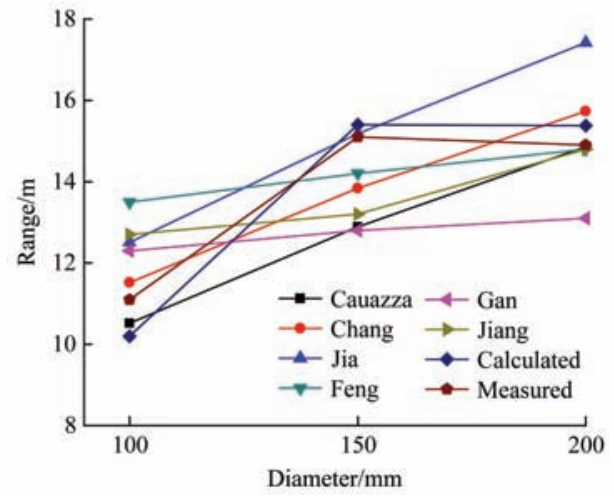

b. Range and pressure

Figure 10 Relationship between range and nozzle diameter

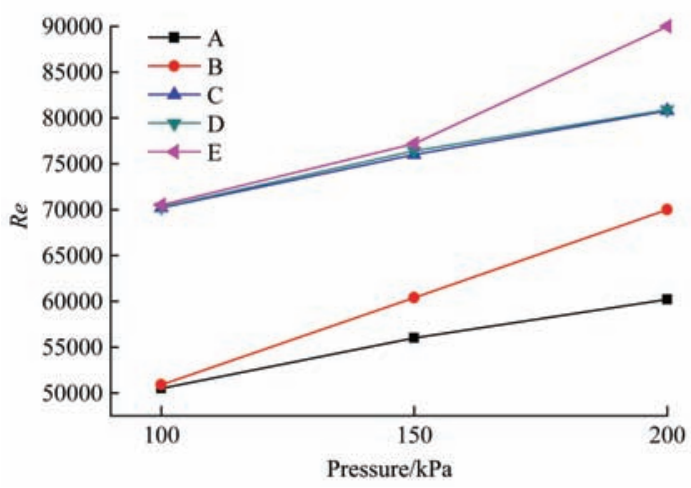

a. $R e$ and pressure

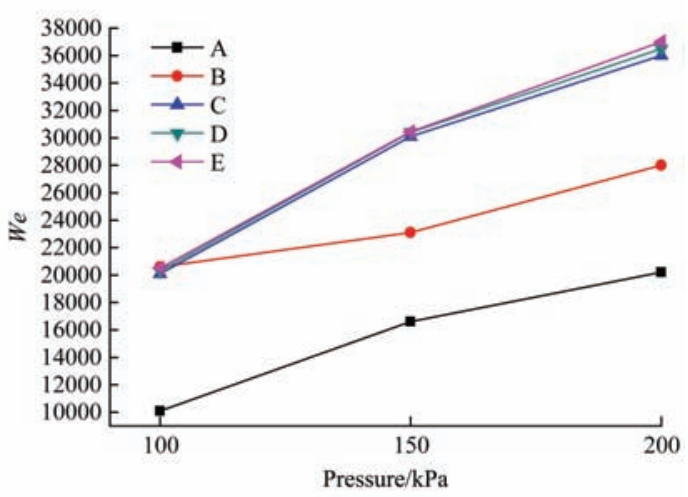

b. We and pressure

Figure 11 Relationship between diameter of nozzle and $R e$, We and pressure 
It was found that $W e$ was proportional to the working pressure, which can be explained based on the Bernoulli's theory. The influence of nozzle diameter, dispersion angle, initial breakup length of the jet, the index equations in equation with respect to $R e$ and $W e$ were given in Equations (12) and (13). The accuracy error was less than $10 \%$, which means the analysis of relationship between jet characteristic lengths and hydraulic diameters of the nozzles was accurate. According to Equation (12), the initial jet breakup length is proportional to $R e$ and $W e$, which further confirms that the initial jet breakup length increased with the increasing of inertia force. Meanwhile, the angle of dispersion was inversely proportional with $R e$ and We in Equation (13), which means that $W e$ had a strong effect on the generation of droplet dispersion. The number $10^{24}$ in the formula can be explained by the influence of other parameters such as surrounding air.

$$
\begin{gathered}
L_{i b}=4.767 R e^{0.211} W e^{0.102} D_{2} \\
\theta=4.18 R e^{24} R e^{-11.982} W e^{7.089} D_{2}
\end{gathered}
$$

where $L_{b}$ is the initial breakup of jet, $\mathrm{mm} ; \theta$ is the angle of dispersion, $\left({ }^{\circ}\right)$; $R e$ is the Reynolds number; $W e$ is the Weber number; and $D_{2}$ is the nozzle diameter, $\mathrm{mm}$.

\section{Conclusions}

This study investigated jet breakup and dispersion characteristics from different sizes of nozzles with a pointed tip fixed dispersion device for impact sprinkler. A new formula of range for the impact sprinkler was established and compared with other formulas, leading to the following important conclusions:

1) The range decreased with the increase in diameter of nozzle, and the largest range of $15.1 \mathrm{~m}$ was produced from sprinkler with 6 $\mathrm{mm}$ nozzle under a working pressure $150 \mathrm{kPa}$.

2) The angle of dispersion decreased with the increase of nozzle size, and the spray coverage from the sprinkler with $6 \mathrm{~mm}$ nozzle got the largest value of $1478 \mathrm{~mm}$ under low pressure, with no significant difference when the pressure was increased.

3) The new formula for calculating range had a high accuracy attested by other formulas and with an average relative error below $3 \%$. Since the formula is based on the angle of dispersion, it could be useful to estimate the uniformity for sprinklers with dispersion device.

4) The relationship between dispersion angle and the initial breakup length of the jet and the nozzle diameter gave formulas that were accurate with errors less than $10 \%$.

\section{Acknowledgements}

This work was supported by the National Natural Science Foundation of China (No.51679109, 51809119), the Natural Science Foundation of Jiangsu Province (BK20170555), the Natural Science Foundation of the Higher Education Institutions of Jiangsu Province (17KJB470001), Special Fund for Ago-scientific Research in the Public Interest of China (201503130).

\section{[References]}

[1] Liljedahl L A. Effect of fluid properties and nozzle parameters on drop size distribution from fan spray nozzles. Iowa State University, Michigan, USA, 1971.

[2] Seginer I, Kantz D, Nir D. The distortion by wind of the distribution patterns of single sprinklers. Agricultural Water Management, 1991; 19:341-359.

[3] Han S, Evans R G, Kroeger M W. Sprinkler distribution patterns in windy conditions. Transactions of the ASAE, 1994; 37(5): 1481-1489.

[4] Li J, Kawano H. Simulating water-drop movement from noncircular sprinkler nozzles. Journal of Irrigation Drainage Engineering, 1995; 121(2): 152-158.

[5] Jiang Y, Li H, Chen C, Xiang Q J. Calculation and verification of formula for the range of sprinklers based on jet breakup length. Int $\mathrm{J}$ Agric \& Biol Eng, 2018; 11(1): 49-57.

[6] Yoon S S. Droplet distribution at the liquid core of a turbulent spray. Physics of Fluids, 2005; 17(3): 035103.

[7] Viswanathan S, Lim D S, Madhumita B R. Measurements of drop size and distribution in an annular two-phase, Two-component flow occurring in a Venturi Scrubber. Industrial \& Engineering Chemistry Research, 2005; 44(19): 7458-7468.

[8] Lehrsch G A, Gallian J J. Oilseed radish effects on soil structure and soil water relations. Journal of Sugar Beet Residue, 2910; 47(2): 1-21.

[9] Li J, Kawano H, Yu K. Droplet size distribution from the different shaped sprinkler nozzle. Transactions of the ASAE, 1994; 37: 1871-1878.

[10] Bedaiwy M N A. Mechanical and hydraulic resistance relations in crust-topped soils. Catena, 2008; 72(2): 270-281.

[11] Taheri M, Sheih C M. Mathematical modelling of atomizing scrubbers. AIChE Journal, 1975; 21(1): 153-157.

[12] Fathikalajahi J, Talaie R, Taheri M. Theoretical study of liquid droplet dispersion in a Venturi scrubber. Journal of the Air \& Waste Management Association, 1995; 45: 181-185.

[13] Fathikalajahi J, Talaie M R, Taheri M. Theoretical study of non-uniform droplet concentration distribution on venturi scrubber performance. Particulate Science and Technology, 1996; 14: 153-164.

[14] Gonçalves J A S, Costa M A M, Henrique P R, Coury J R. Atomization of liquids in a Pease-Anthony venturi scrubber: Part I. Jet dynamics. Journal of Hazardous Materials, 2003; 97: 267-279.

[15] Lefebvre A H. Atomization and sprays. Hemisphere Publishing Corporation, New York, USA, 1989.

[16] Ohrn T R, Senser D W, Lefebvre A H. Geometric effects on spray cone angle for plain nozzle atomizers. Atomization and Sprays, 1991; 1(3): 253-268.

[17] Chen S K, Lefebvre A H. Spray cone angles of effervescent atomizers. Atomization and Sprays, 1994; 4(3): 291-301.

[18] Ruiz F, Chigier N. Parametric experiments on liquid jet atomization spray angle. Atomization and Sprays, 1991; 1(1): 23-45.

[19] Abramovich G N. Theory of turbulent jets. MIT Press, Cambridge, MA, UK, 1963.

[20] Yokota, K.; Matsuoka, S. An experimental study of fuel spray in a diesel engine. Transactions of the Japanese Society of Mechanical Engineers, 1977; 43: 3455-3464.

[21] Reitz R D, Bracco F V. On the dependence of spray angle and other spray parameters on nozzle design and operating conditions. SAE Paper No.790494, 1979.

[22] Viswanathan S, Pierre St C, Gnyp A W. Jet penetration measurements in a Venturi scrubber. Canadian Journal of Chemical Engineering, 1983; 61: 504-508.

[23] Fathikalajahi J, Talaie M R, Taheri M. Theoretical study of liquid droplet dispersion in a Venturi scrubber. Journal of the Air \& Waste Management Association, 1995; 45: 181-185.

[24] Gonçalves J A S, Costa M A M, Henrique P R, Coury J R. Atomization of liquids in a Pease-Anthony Venturi scrubber: Part I. Jet dynamics. Journal of Hazardous Materials, 2003; 97: 267-279.

[25] Hsiang L, Faeth G. Near-limit drop deformation and secondary breakup. International Journal of Multiphase Flow, 1992; 18: 635-652.

[26] Kotsovinos N E. A note on the spreading rate and virtual origin of a plane turbulent jet. Journal of Fluid Mechanics, 1976; 77: 305-311.

[27] Varde K S, Popa D M, Varde L K. Spray angle and atomization in diesel sprays. SAE Paper No.841055, 1984

[28] American Society of Agricultural and Biological Engineers. ASABE Standards (R2007). S398.1: Procedure for sprinkler testing and performance reporting. St Joseph, Mich., MI. USA, 2007.

[29] Li J, Kawano H, Yu K. Droplet size distribution from the different shaped sprinkler nozzle. Transactions of the ASAE, 1994; 37: 1871-1878.

[30] Zhu X Y, Yuan S Q, Liu J P. Effect of sprinkler head geometrical parameters on hydraulic performance of fluidic sprinkler. J Irrig Drain Eng ASCE, 2012; 138(11): 1019-1026.

[31] Gregory C T, Alarecon J J. Rotary sprinkler nozzle for enhancing close-in water distribution. U.S. Patent No. 7325753B2, 2008. 
[32] ISO 7749-1:1995. Agricultural irrigation equipment-Rotating sprinklers. 1995.

[33] Li J S. Sprinkler performance as function of nozzle geometrical parameters. Journal of Irrigation and Drainage Engineering-ASCE, 1996; 122(4): 244-247.

[34] Jiang Y, Chen C, Li H, Xiang Q J. Influences of nozzle parameters and low-pressure on jet breakup and droplet characteristics. Int J Agric \& Biol Eng, 2016; 9(4): 22-32.

[35] Chillman A, Ramulu M, Hashish M. Waterjet and water-air jet surface processing of titanium alloy: a parametric evaluation. Journal of
Manufacturing Science Engineering, 2010; 132(1): 011012.

[36] Kohnen B T, Musemic E, Straburger F, Kupper B, Walzel P. Measurement of the droplet size distribution of a full cone nozzle. 23rd Annual Conference on Liquid Atomization and Spray System, Brno, Czech Republic, 2010; pp.22-32.

[37] Hamid A H A, Atan R L, Noh M H M, Rashid H. Spray cone angle and air core diameter of hollow cone swirl rocket injector. IIUM Engineering Journal, Special Issue on Mechanical Engineering, 2011; 12: 1-9.

[38] Hsiang L, Faeth G. Near-limit drop deformation and secondary breakup. International Journal of Multiphase Flow, 1992; 18: 635-652. 